\title{
The adoption of social media by small and medium enterprise: a systematic literature review
}

\author{
Ahmed Abdullah Alhamami ${ }^{1}$, Noor Azuan Hashim ${ }^{2}$, Roshayati Abdul Hamid ${ }^{3}$, \\ Siti Ngayesah Ab. Hamid ${ }^{4}$ \\ 1,2,3,4 Faculty of Economics and Management, The National University of Malaysia, Selangor, Malaysia \\ ${ }^{1}$ College of Administrative Sciences, Najran University, Najran Saudi Arabia
}

\begin{tabular}{l} 
Article Info \\
\hline Article history: \\
Received Jun 14, 2021 \\
Revised Sep 12, 2021 \\
Accepted Sep 21, 2021 \\
\hline
\end{tabular}

Keywords:

Business performance

SMEs

Social media

TOE

\begin{abstract}
Social media (SM) has become a necessity and a method to confront challenges and fierce competition. More than half of the population are using SM. However, its implication for small and medium enterprises (SMEs) is not well documented and researched. Therefore, the purpose of this study is to review the literature pertaining to the adoption of SM by SMEs. A systematic literature review was conducted using specific keywords and database. This has resulted in reviewing 28 related articles. The findings was presented using frequency analysis. Number of articles are increasing steadily especially in emerging markets with large number of studies deploying the exploratory nature. The most widely used theory is the technological-organizational-environmental framework (TOE) and the sample size of the reviewed studies is adequate. Increasingly the structural equation modelling are being used. However, the use of intervening variable is minimal. The finding also showed that organizational and environmental context variables are the most important predictors of SM adoption by SMEs while the consequence of this adoption on business performance is mixed. There is a need for more studies to discover the consequence of adopting SM by SMEs using a combination of theories.
\end{abstract}

This is an open access article under the CC BY-SA license.

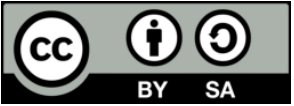

\section{Corresponding Author:}

Ahmed Abdullah Alhamami

Faculty of Economics and Management

The National University of Malaysia

43600 UKM Bangi, Selangor, Malaysia

Email: alhamami1a@gmail.com

\section{INTRODUCTION}

Recently, the social media (SM) has become an important tool for individual, business and governmental agencies to communicate and spread news about their activities. By April 2021, number of SM users account to 4.83 billion with an annual increase of $13.7 \%$. It is estimated that almost $70 \%$ of the eligible population in the world are using SM website with an average use of 2 hours and 22 minutes per day [1]. Due to this wide usage of SM, researchers, practitioners and businesses has started using the SM as a tool to access and communicate with potential customers [2]. One of the important usage of SM is to market product and services and increase the awareness about brand as well as brand loyalty [3]. Despite the fact that there is a variation in the usage of the SM websites, businesses are deploying more frequently the facebook (FB) as a tool to market their product and services and interact with customers using two-way communications. Among the other SM that are used is twitter, linkedin, youtube and blogs [3]. Researchers indicate the usage of SM has become a must for business to survive and thrive [4]-[7], [8]. 
One of the business that not yet utilize the potential of SM is the small and medium enterprise (SMEs). SMEs are characterized by their small size and capability [4], [9]. The use of SM can be an optimal solution for these business to grow and compete with other organizations [10]. This is because the SMEs are facing growing challenges due to the fierce competition and the globalization [11]. However, the adoption of SM by SMEs is still under researched [11]-[13] and more studies are needed to understand the status quo of the SM adoption [12]. Despite the urgent need for SMEs to use the SM, the literature has no agreement on the role that can be played by SM in term of business performance. Researchers found that the use of SM does not affect the business performance of SMEs [14]-[16]. On the other hand, researchers also found that the SM has resulted in an improvement of the financial performance of SMEs [3], [11], [17], [18] and increase the reputation as well as brand awareness and reduce cost of operation for these SMEs [17], [19].

In addition, the literature also showed that there is no general agreement on the predictors that lead to the adoption of SM among SMEs. While some researchers found that the organizational and environmental factors are critical [20], others tend to think that the technological factors carry the same importance [21]. The findings regarding the predictors and the role of SM are mixed. In addition, the literature lack for studies of SM adoption and its impact on SMEs [12], [13]. Therefore, the purpose of this study is to review the literature related to the adoption of SM by SMEs. The study also aims to find literatures on predictors of SM adoption by SMEs and also consequences of adopting SM. This will provide the researcher the direction for future work. In the next section, the literature is reviewed systematically. This is followed by the research methodology and the findings of SLR from this study. The findings are discussed as well as the limitations and direction for future works are highlighted. A concluding remark is given at the last section.

\section{LITERATURE REVIEW}

The literature review of this study included 28 articles that deal with the adoption of SM by SMEs. The articles were divided based on the theoretical frameworks of the reviewed studies.

\subsection{Exploratory studies}

Exploratory studies refer to the situation where the reviewed articles have not deployed a theory. For example, in the study of [3] in India, the study reviewed the literature and found that facebook is the most widely used tool for the marketing using SM. Similarly, a review study conducted by [22] found that the studies pertaining to SM in developing countries is still limited. The study of [10] in United Kingdom (UK) conducted a survey to understand the adoption of SM by SMEs. Findings showed that twitter and facebook are widely used by SMEs and these SMEs are benefiting greatly from the usage of SM. In France, the study of [18] found that strategic orientation affected SM orientation which in turn affected the SM performance.

More explorative in nature studies were conducted by researchers. In the study of [23] in United States (US), the author examined the SM adoption using a qualitative approach. The findings showed that perception of SM such as ease of use, usefulness, and enjoyment as well as personal characteristics, social influence, current business performance, and business purposes are important factors for the SM adoption. Similarly, a study by [11] in UK using a qualitative approach found that SM enhances the visibility of companies and increase their sales and access to new market. In Australia, [24] found that the facilitators for adoption is the ease of use, peer use, knowledge to use and relative advantage. For non-adopters, the time requirement and lack of knowledge is the main barrier. Facebook followed by YouTube are widely used by SMEs. Review studies were also conducted to understand the benefits of adopting SM by SMEs and found that the main benefits are related to brand reputation, marketing, advertisement, and customer relationship management [25], [26]. In Finland, the study of [27] examined the predictor of using SM and found that prior online sale and high use of information communication technology (ICT) will motivate SMEs to adopt the SM.

\subsection{Technological-organizational-environmental}

Several theories have been used to study innovation adoption by several researchers. Among them are technological-organizational-environmental (TOE), diffusion of innovation (DOI). TOE framework has been used by several studies in the literature. In a multi countries study, [2] examine the adoption of SM by SMEs and found that firm innovativeness, firm size and firm geographical location have significant effect on SM adoption. In Malaysia, [28] deployed TOE to examine the adoption of social customer relationship management. The findings showed that technological, organizational and environmental context are important for the adoption of SM by SMEs. Similarly, the TOE was used in the study of [20] in Uni Emirat Arab (UAE) and the findings showed that organizational and environmental context are critical for the adoption but not the technological. Similar findings were derived by [14] which found that only 
organizational and environmental factor affected the SM adoption. SM adoption has no effect on business performance. On the other hand, the study of [21] indicate that SM awareness, technological, organizational, and environmental context affected the intention to use SM marketing during coronavirus disease (COVID 19). In addition, technological, organizational, and environmental factors affected the use of SM by SMEs in UAE [12].

\subsection{Technology acceptance model}

Technology acceptance model (TAM) is one of the widely used theoretical framework in technology adoption and it was developed by [29]. In the context of SM adoption by SMEs, the model was used in few studies. In Malaysia, [30] deployed TAM to examine the use of SM. The findings indicate that the most important variable are ease of use, usefulness, and enjoyment. Similarly, in Switzerland, [31] examined the adoption of SM for strategic use and found that perceived usefulness and perceived risk but not ease of use has significant effect on the adoption of SM. In the study of [16] in US, the findings showed that personal use of SM for business purposes outperform business use. The ease of use and usefulness are critical. Personal and business use of SM has no effect on revenue. In the study of [32], the findings showed that perceived usefulness, perceive ease of use and perceived trust affect the intention to use SM by SMEs in Malaysia.

\subsection{Unified theory of acceptance and use of technology (UTAUT)}

The unified theory of acceptance and use of technolog (UTAUT) is one of the theory that has been used by researchers to examine the adoption of SM by SMEs. UTAUT was used in the study of [33] to examine the behavioural intention of SMEs to adopt SM. The findings showed that price value and task technology fit affected attitude which in turn along with facilitating condition affected behavioural intention (BI). In the study of [34], UTAUT was also deployed and the findings showed that performance expectancy, social influence, and facilitating condition affected the BI toward using SM for SMEs marketing.

\subsection{Diffusion of innovation}

Few of the reviewed studies has used the DOI theory to explain the adoption of SM by SMEs. For instance, [17] examined the adoption of facebook in Malaysia and found that Facebook usage affected the financial performance. Compatibility, cost effectiveness, and interactivity affected the usage of facebook. Trust has insignificant effect. DOI was also deployed in the study of [19] and the author found that interactivity, cost effectiveness, and compatibility affected the SM usage which in turn affected the performance benefits.

\subsection{Other theories}

Two studies have deployed different theories such as the viral marketing theory and media synchronicity theory (MST). The viral marketing theory was deployed in the study of [13] and the findings showed that SM helps SMEs in increase customer clientele, brand awareness, loyalty and reputation, reduce communication and marketing cost, revenue generation, attracting new customers, and competitive advantage. In the study of [35], the MST was deployed using qualitative approach and the findings showed that the usage of SM is affected by variable with information security and control as emerging important variable. The usage includes marketing, innovation, and collaboration.

\section{RESEARCH METHODOLOGY}

The study uses a quantitative approach that is done by reviewing existing studies in SM adoption by SMEs. To identify the most related articles to the topic, keywords have been used to search reliable databases. Keywords such as social media, SMEs, SM, social media adoption by SMEs and a combination of these words have been used to search for articles in web of sciences, scopus, and google scholar. Inclusion criteria were assigned to include articles in English between 2015 and 2021. On the other hand, the exclusion criteria were set to exclude article in non-English language before 2015. The purpose of time frame between 2015-2020 is to have a recent view of the literature regarding the topic of this study. Using these criteria, a total of 141 articles were identified to be related to the topic by using the keywords. However, the filtration of articles has reduced the number of articles to 27 articles. One more article was included from 2014 due to its relatedness to the topic. This makes the total reviewed articles is 28 articles. The filtration included three phases. Duplicated and non-English, outdated articles (first phase of filtration) reduced the articles to 57 followed by reading of title and abstract which has reduced the number to 38 and the last phase conducted by full reading the articles and resulted in 28 valid articles. Figure 1 shows the filtration process of selecting the related articles. 


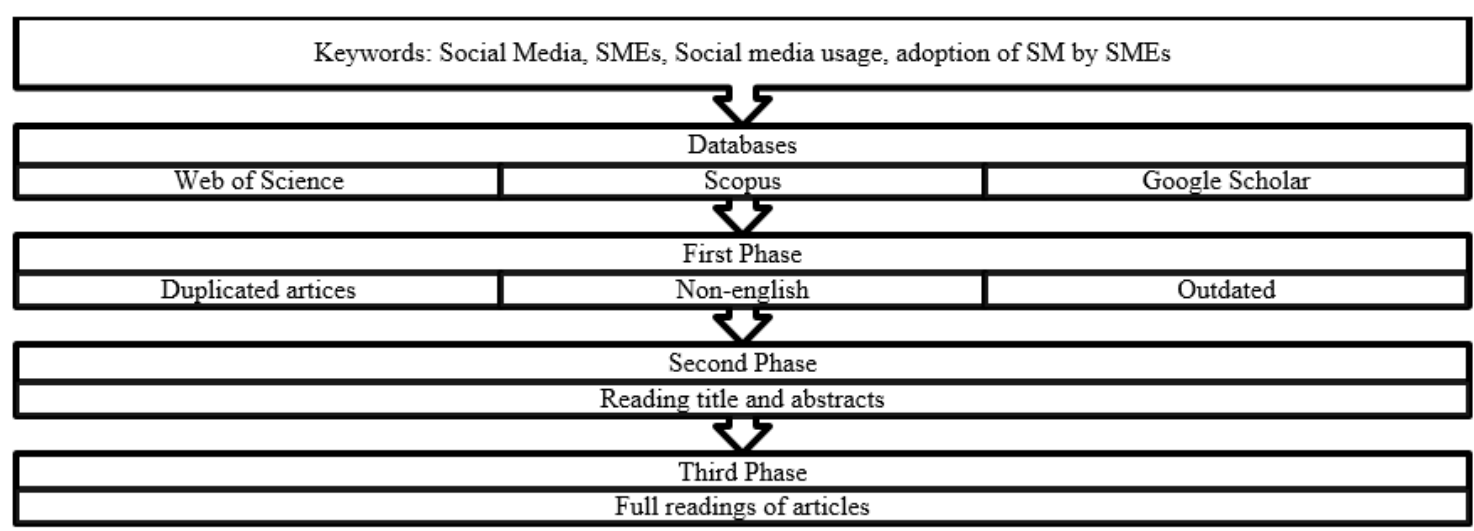

Figure 1. Filtration of articles

\section{FINDINGS}

The findings of systematic literature review? This study are presented using frequency analysis. It is conducted by using excel sheet that helps in drawing the figures. The findings include the descriptive information of the reviewed articles such as year of publication, country, study approach, sample, data analysis technique, predictor of adoption and consequence.

\subsection{Year of publication}

In Figure 2, the year of publication of the articles is given. It shows that number of articles increased steadily over the years. In 2017, the highest number recorded. Sharp drop has been seen in 2018. In 2019 and 2020, the number of articles increased. This might be due to the notion that the SM has become a necessity for businesses.

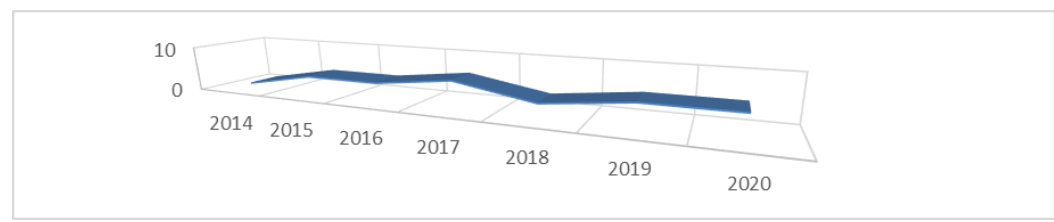

Figure 2. Year of publication

\subsection{Country of the Study}

The country of origin where the reviewed studies has been conducted is given in Figure 3. It shows that the highest percentage of $14 \%$ was conducted in UAE and Malaysia as well as India (14\% for each). In the second rank is the country of US, UK and Indonesia with $10 \%$ for each country. Other countries except Australia (7\%) received less than $5 \%$ of the studies.

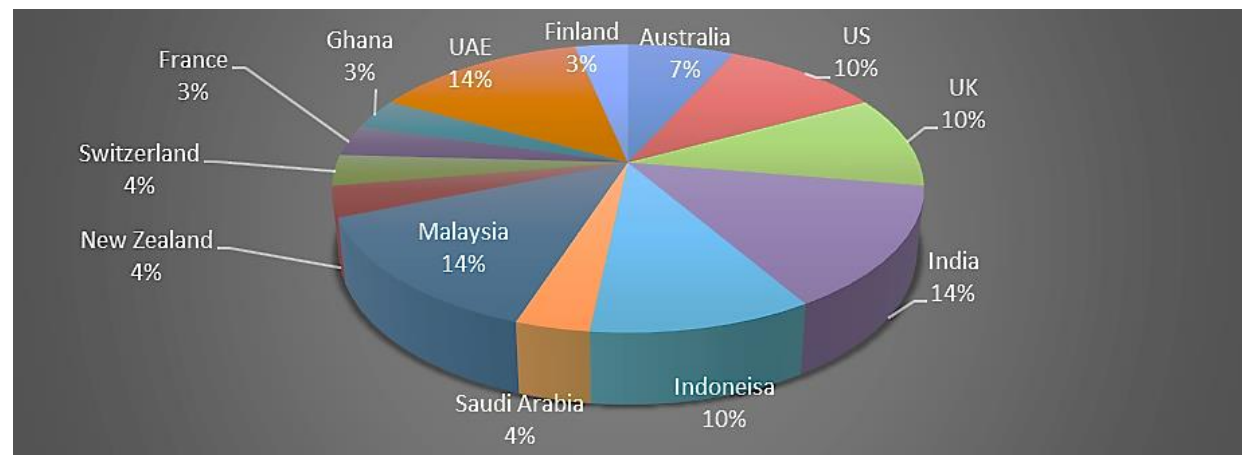

Figure 3. Country of the study

The adoption of social media by small and medium enterprise: a systematic... (Ahmed Abdullah Alhamami) 


\subsection{Theoretical framework}

Theories that have been deployed by the reviewed studies are shown in Figure 4. It shows that $38 \%$ of the reviewed studies did not deploy any theory and they were explorative in nature. Among the deployed theory, the TOE received $21 \%$ of the reviewed studies. This is followed by TAM (17\%), UTAUT (10\%), DOI (7\%), MST (4\%), and viral marketing (3\%). It was noticed also that most of the studies did not combine theories to increase the variation in SMEs' adoption of SM.

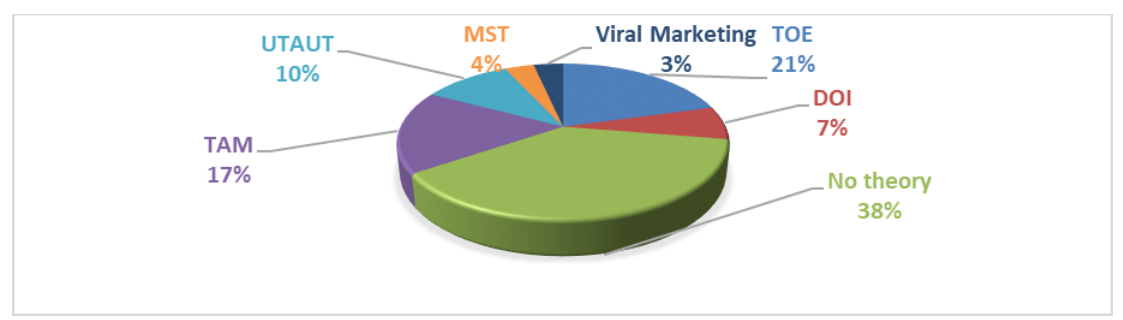

Figure 4. Theoretical framework

\subsection{Study approach}

The approach of the reviewed studies can be divided into three categories. The first is the empirical studies which include qualitative and quantitative studies. This category accounted to $75 \%$. Review studies accounted to $21 \%$ while studies that were conceptual in nature accounted to $4 \%$. Figure 5 shows the approach of the reviewed studies.

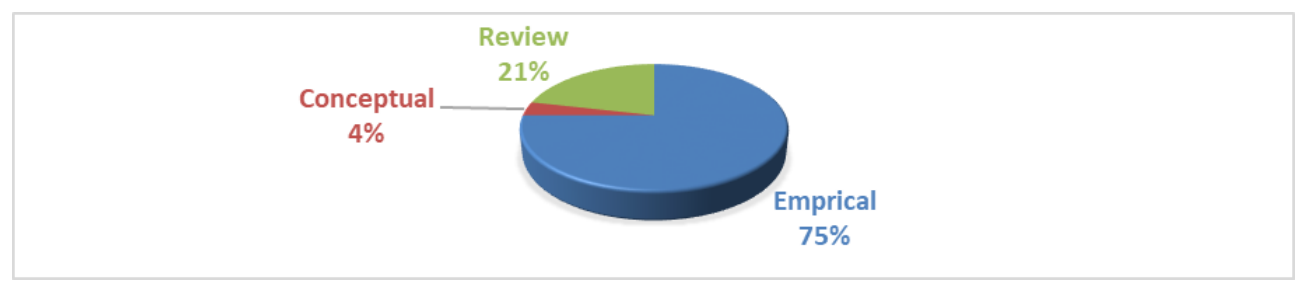

Figure 5. Approach of the reviewed studies

\subsection{Sample size}

The sample size of the empirical studies is given in Figure 6. It shows that the sample size ranged between 42 as minimum and 6,129 as a maximum with a mean of 542. This sample size is large enough to represent the population and it meets the assumptions of structural equation modelling [36]. Among the respondents of the reviewed studies, the majority were the manager of SMEs except for two studies extracted the data from entrepreneurs.

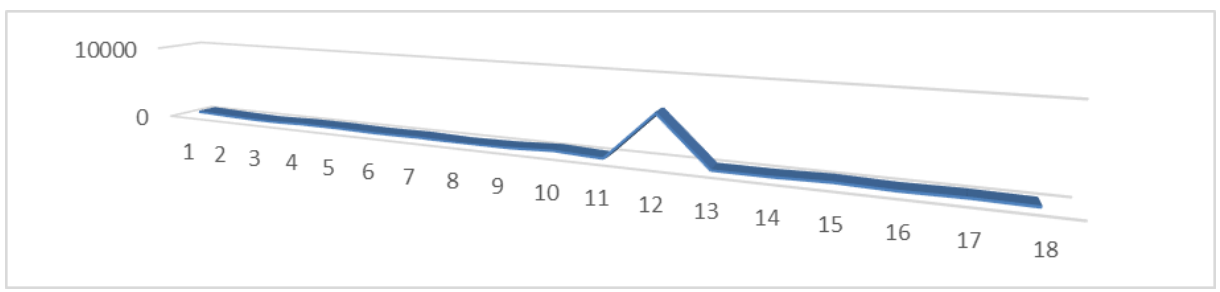

Figure 6. Sample size of the reviewed studies

\subsection{Data analysis tools}

The method of analysing the data of the empirical studies are shown in Figure 7. It shows that equally the statistical package for social science (SPSS) and partial least square (PLS) has been deployed by seven studies for each. The analysis of moment structure (AMOS) was deployed in three studies. Four studies were qualitative in nature and deployed the content analysis. 


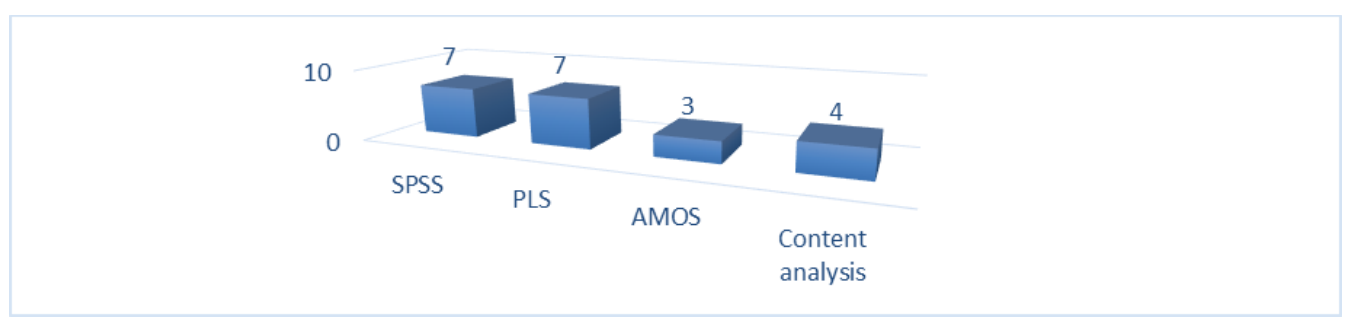

Figure 7. Data analysis tools

\subsection{Predictors and consequence of social media adoption}

The reviewed studies indicated that the predictors of SM varied. While some studies refer to cost as an essential factor [17], [28], others view the environmental factors such as competitive pressure and customer pressure as the most critical driver for SM adoption [20]. Previous studies agreed that the technological context is not critical for the adoption of SM [14], [20]. On the other hand, studies also found that the technological context is important [12], [21]. The differences in the previous studies could be related to the country where the study is conducted. This is because there is a technological gap between developed and developing countries. However, previous studies that found the importance of technology outperform those that found the variable is not important. In term of the consequence, the previous studies have mixed opinion. Research found that the SM does not affect the performance of SMEs while other found significant effect of SM's adoption on financial performance. This is again could be due to the country of origin and due to the notion that adoption of technology is costly and it pays off in the short term.

\section{DISCUSSION}

This study was conducted to review the existing studies in SM adoption by SMEs. The findings showed that number of studies are increasing steadily over the years and this shows the importance of SM for SMEs to survive and thrive. This findings is in line with the study of [8] and [10] which indicate that the adoption has become a must for SMEs. The findings also showed that the number of article in developing countries and emerging economies are increasing. More than half of the articles were conducted in countries such as UAE, Malaysia, India, and Indonesia. This finding contradicts with the suggestions of [13] which indicated that most of previous studies were conducted in developed countries. However, the topic of adopting SM by SMEs is still in its infancy and this is evident from the large number of studies which were explorative in nature and did not deploy theories. In agreement with this conclusion, [27] suggested that the research into SM adoption by SMEs is still in its early stage and there are rooms to grow. Among the widely used theories in the reviewed studies is the TOE followed by TAM and UTAUT. The finding also showed that the empirical studies are increasing and they have deployed adequate number of respondents using several data analysis techniques such as SPSS, PLS and AMOS. In term of the predictors of SM adoption by SMEs, the studies found that organizational and environmental factors are the most important. This can explain the usage of TOE which is an organizational level adoption theory while TAM and UTAUT are designed for individual adoption of technology [37]. In term of the consequence of adopting SM by SMEs, the findings showed that there are mixed findings with the positive effect outperform the negative or the insignificant effect.

\section{LIMITATION AND DIRECTION FOR FUTURE WORK}

The findings of this study should be interpreted bearing in mind the limitations of this study. This study is limited to the timeframe between 2015 and 2020. It is also limited to the number of reviewed studies. As a way to expand the findings of this study, it is suggested for future work to include larger sample size by enlarging the timeframe or by including more databases. Future studies are suggested to examine the adoption of SM by SMEs in the context of developing countries. Few studies on this topic in countries in the Middle East such as Saudi Arabia, but more studies in other developing countries such as Turkey, Iran, and African. Using these literature from these countries will help in understand the predictor of SM adoption. Further, due to the differences in the nature of service and manufacturing SMEs, future studies are suggested to conduct more studies on either service or manufacturing SMEs.

In term of the theories, previous studies rarely combine more than one theory to increase the variation in explaining the SM adoption by SMEs. Therefore, it is recommended for future studies to examine the adoption of SM by combining TOE and TAM or TOE and social exchange theory or TOE and UTAUT. This is

The adoption of social media by small and medium enterprise: a systematic... (Ahmed Abdullah Alhamami) 
because combining theories in technology adoption is the norm of the literature. For example UTAUT was developed based on combining eight theories [38]. Further, individual context variable can be included in TOE to enhance the model. For example, the characteristics of the managers of SMEs such as their age, gender, education, and experience [39] can play a critical role in explaining their behaviour toward adopting SM.

Future studies are also recommended to conduct more empirical studies and deploy the structural equation modelling. SPSS is widely used in the literature and this can explain the lack of using mediator and moderator. The reviewed studies did not include any intervening variables such as mediator or conditional variable such as moderator. For example, trust is critical factor in technology adoption and including this variable as mediator or moderator can increase the variation in SM adoption by SMEs. Other important variable such as IT knowledge and organizational readiness can be also deployed as moderating variables in the context of SM adoption [37]. Lastly, there are scarce studies that focus on predictors and consequence SM and SMEs. This topic deserves further research to understand comprehensively the role of SM in SMEs.

\section{CONCLUSION}

This study has reviewed the literature related to SM adoption by SMEs. Frequency analysis was used to present the findings of this study. The findings indicate the number of articles are increasing over year and these studies are being conducted in emerging economies. The findings also showed that there are large number of exploratory studies indicating that the study in SM adoption by SME are still in its early stage and more studies are needed. Most widely used theory is the TOE and this could be due to the organizational nature of the theory. The findings also showed that the literature is dominated by empirical studies with adequate sample size. This also could explain the increase use of structural equation modelling. The most important predictors of SM adoption by SMEs are organizational and environmental context variables and the consequence of the adoption is mixed. More studies in emerging economies are needed to confirm the consequence of adopting SM by SMEs.

\section{REFERENCES}

[1] Data Reportal, "Global Social Media Stats.” Datareportal.com. https://datareportal.com/social-media (accessed June, 10, 2021).

[2] S. F. Wamba and L. Carter, "Social media tools adoption and use by SMES: An empirical study," Journal of Organizational and End User Computing, vol. 26, no. 2, pp. 1-17, 2014, doi: 10.4018/joeuc.2014040101.

[3] S. Karimi and H. S. Naghibi, "Social media marketing (SMM) strategies for small to medium enterprises (SMEs)," Int. J. Information, Bus. Manag., vol. 7, no. 4, pp. 86-99, 2015.

[4] S. Chauhan, R. Banerjee, C. Chakraborty, M. Mittal, A. Shiva, and V. Ravi, "A self-congruence and impulse buying effect on user's shopping behaviour over social networking sites: an empirical study," Int. J. Pervasive Comput. Commun., 2021, doi: 10.1108/IJPCC-01-2021-0013.

[5] R. Wang, F. Zeng, L. Yao, and J. Wu, "Game-theoretic algorithm designs and analysis for interactions among contributors in mobile crowdsourcing with word of mouth," IEEE Internet of Things Journal, vol. 7, no. 9, pp. 8271-8286, 2020, doi: 10.1109/JIOT.2020.2989745.

[6] R. Atat, L. Liu, J. Wu, G. Li, C. Ye, and Y. Yang, "Big data meet cyber-physical systems: A panoramic survey," IEEE Access, vol. 6, pp. 73603-73636, 2018, doi: 10.1109/ACCESS.2018.2878681.

[7] J. Wu, S. Guo, H. Huang, W. Liu, and Y. Xiang, "Information and communications technologies for sustainable development goals: state-of-the-art, needs and perspectives," IEEE Communications Surveys \& Tutorials, vol. 20, no. 3, pp. 2389-2406, 2018, doi: 10.1109/COMST.2018.2812301.

[8] S. Ainin, F. Parveen, S. Moghavvemi, N. I. Jaafar, and N. L. M. Shuib, "Factors influencing the use of social media by SMEs and its performance outcomes," Industrial Management \& Data Systems, vol. 115, no. 3, pp. 570-588, 2015, doi: 10.1108/IMDS-07-2014-0205.

[9] H. H. Attar, A. A. A. Solyman, A. Alrosan, C. Chakraborty, and M. R. Khosravi, "Deterministic cooperative hybrid ring-mesh network coding for big data transmission over lossy channels in 5G networks," EURASIP Journal on Wireless Communications and Networking, vol. 2021, no. 1, pp. 1-18, 2021, doi: 10.1186/s13638-021-02032-z.

[10] M. McCann and A. Barlow, "Use and Measurement of Social Media for SMEs," Journal of Small Business and Enterprise Development, vol. 22, no. 2, pp. 241-249, 2015, doi: 10.1108/JSBED-08-2012-0096.

[11] R. Bocconcelli, M. Cioppi, and A. Pagano, "Social media as a resource in SMEs' sales process," Journal of Business \& Industrial Marketing, vol. 32, no. 5, pp. 693-709, 2017, doi: 10.1108/JBIM-11-2014-0244.

[12] A. R. Abu Bakar, S. Z. Ahmad, and N. Ahmad, "SME social media use: A study of predictive factors in the United Arab Emirates,” Glob. Bus. Organ. Excell., vol. 38, no. 5, pp. 53-68, 2019, doi: 10.1002/joe.21951.

[13] S. Z. Ahmad, N. Ahmad, and A. R. Abu Bakar, "Reflections of entrepreneurs of small and medium-sized enterprises concerning the adoption of social media and its impact on performance outcomes: Evidence from the UAE," Telematics and Informatics, vol. 35, no. 1, pp. 6-17, 2018, doi: 10.1016/j.tele.2017.09.006.

[14] S. Z. Ahmad, A. R. Abu Bakar, and N. Ahmad, "Social media adoption and its impact on firm performance: the case of the UAE," Int. J. Entrep. Behav. Res., vol. 25, no. 1, pp. 84-111, 2019, doi: 10.1108/IJEBR-08-2017-0299. 
[15] S. Chatterjee and A. Kumar Kar, "Why do small and medium enterprises use social media marketing and what is the impact: Empirical insights from India," International Journal of Information Management, vol. 53, 2020, doi: 10.1016/j.ijinfomgt.2020.102103.

[16] M. C. Gavino, D. E. Williams, D. Jacobson, and I. Smith, "Latino entrepreneurs and social media adoption: personal and business social network platforms," Management Research Review, vol. 42, no. 4, pp. 469-494, 2019, doi: 10.1108/MRR-02-2018-0095.

[17] F. Parveen, N. I. Jaafar, and S. Ainin, "Social media usage and organizational performance: Reflections of Malaysian social media managers," Telemat. Informatics, vol. 32, no. 1, pp. 67-78, 2014, doi: 10.1016/j.tele.2014.03.001.

[18] V. Dutot and F. Bergeron, "From strategic orientation to social media orientation: improving SMEs' performance on social media," Journal of Small Business and Enterprise Development, vol. 23, no. 4, pp. 1165-1190, 2016, doi: 10.1108/JSBED-11-2015-0160.

[19] R. Odoom, T. Anning-Dorson, and G. Acheampong, "Antecedents of social media usage and performance benefits in small- and medium-sized enterprises (SMEs)," Journal of Enterprise Information Management, vol. 34, no. 1, pp. 1-5, 2017, doi: 10.1108/JEIM-04-2016-0088.

[20] A. AlSharji, S. Z. Ahmad, and A. R. Abu Bakar, "Understanding social media adoption in SMEs: Empirical evidence from the United Arab Emirates," Journal of Entrepreneurship in Emerging Economies, vol. 10, no. 2, pp. 302-328, 2018, doi: 10.1108/JEEE-08-2017-0058.

[21] M. I. Effendi, D. Sugandini, and Y. Istanto, "Social Media Adoption in SMEs Impacted by COVID-19: The TOE Model," The Journal of Asian Finance, Economics, and Business, vol. 7, no. 11, pp. 915-925, 2020, doi: ence.or.kr/article/JAKO202032462597184.page.

[22] S. S. Abed, Y. K. Dwivedi, and M. D. Williams, "SMEs' adoption of e-commerce using social media in a Saudi Arabian context: A systematic literature review," International Journal of Business Information Systems, vol. 19, no. 2, pp. 159-179, 2015, doi: 10.1504/IJBIS.2015.069429.

[23] W. He, F. K. Wang, Y. Chen, and S. Zha, "An exploratory investigation of social media adoption by small businesses," Inf. Technol. Manag., vol. 18, no. 2, pp. 149-160, 2017, doi: 10.1007/s10799-015-0243-3.

[24] S. Burgess, C. Sellitto, C. Cox, J. Buultjens, and S. Bingley, "An Innovation Diffusion Approach to Examining the Adoption of Social Media by Small Businesses: an Australian Case Study," Pacific Asia Journal of the Association for Information Systems, vol. 9, no. 3, pp. 1-24, 2017, doi: 10.17705/1pais.09301.

[25] M. Yadav, "Social media as a marketing tool: Opportunities and challenges," Indian Journal of Marketing, vol. 47, no. 3, pp. 16-28, 2017.

[26] A. Kumar, and N. Ayedee, "Social Media Tools for Business Growth of SMEs," Journal of Manangement, vol. 5, no. 3, pp. 137-142, 2018.

[27] H. Koski, M. Pajarinen, and P. Rouvinen, "What company characteristics are associated with the adoption of social media?," Industry and Innovation, vol. 26, no. 8, pp. 880-897, 2019, doi: 10.1080/13662716.2019.1566054.

[28] A. Ahani, N. Z. A. Rahim, and M. Nilashi, "Forecasting social CRM adoption in SMEs: A combined SEM-neural network method," Computers in Human Behavior, vol. 75, pp. 560-578, 2017, doi: 10.1016/j.chb.2017.05.032.

[29] F. D. Davis, "Perceived Usefulness, Perceived Ease of Use, and User Acceptance of Information Technology," MIS quarterly, vol. 13, no. 3, pp. 319-340, 1989, doi: 10.2307/249008.

[30] S. A. Razak, D. Nor, A. Bin, and M. Latip, "Factors That Influence The Usage of Social Media In Marketing," Quest Journals J. Res. Bus. Manag., vol. 4, no. 2, pp. 2347-3002, 2016.

[31] M. Beier and K. Wagner, "Social media adoption: Barriers to the strategic use of social media in SMEs," In 24th Eur. Conf. Inf. Syst. (ECIS), 2016.

[32] A. T. Ramachandran, N. Ahmad, S. Miskon, N. A. Iahad, and N. M. Ali, "Factors influencing the adoption of social media in service sector small and medium enterprises (Smes)," Adv. Intell. Syst. Comput., vol. 1073, no. 8, pp. 917-925, 2020, doi: 10.1007/978-3-030-33582-3_86.

[33] S. Vatanasakdakul, C. Aoun, and Y. H. S. Putra, "Social media in micro-enterprises: Exploring adoption in the Indonesian retail sector," Journal of Global Information Management, vol. 28, no. 3, pp. 184-203, 2020, doi: 10.4018/JGIM.2020070110.

[34] F. A. Abdat, "Using UTAUT Model to Predict Social Media Adoption among Indonesian SMEs," Saudi J. Econ. Financ., vol. 4, no. 10, pp. 498-505, 2020, doi: 10.36348/sjef.2020.v04i10.003.

[35] W. Y. C. Wang, D. J. Pauleen, and T. Zhang, "How social media applications affect B2B communication and improve business performance in SMEs," Industrial Marketing Management, vol. 54, pp. 4-14, 2016, doi: 10.1016/j.indmarman.2015.12.004.

[36] Hair, T. M. Hult, C. M. Ringle, and M. Sarstedt, "A Primer on Partial Least Squares Structural Equation Modeling (PLS-SEM),” In Sage publications, 2nd ed. Thousand Oakes, 2017.

[37] M. Kayali, N. Safie, and M. Mukhtar, "The Effect of Individual Factors Mediated by Trust and Moderated by IT Knowledge on Students' Adoption of Cloud Based E -learning,” Int. J. Innov. Technol. Explor. Eng., vol. 9, no. 2, 2019, doi: 10.35940/ijitee.J1137.129219.

[38] V. Venkatesh, M. Morris, G. Davis, and F. Davis, "User Acceptance of Information Technology: Toward a Unified View," MIS quarterly, vol. 27, no. 3, pp. 425-478, 2003, doi: 10.2307/30036540.

[39] V. Venkatesh, J. Y. L. Thong, and X. Xu, "Consumer Acceptance and Use of Information Technology: Extending the Unified Theory of Acceptance and Use of Technology," MIS quarterly, vol. 36, no. 1, pp. 157-178, 2012. 